\title{
2014 International Society for Disease Surveillance Conference Translating Research and Surveillance into Action
}

The International Society for Disease Surveillance (ISDS) will hold its thirteenth annual conference in Philadelphia on December 10th and 11th, 2014. The society's mission is to improve population health by advancing the science and practice of disease surveillance, and the annual conference advances this mission by bringing together practitioners and researchers from multiple fields involved in disease surveillance, including public health, epidemiology, health policy, biostatistics and mathematical modeling, informatics and computer science. This year the conference received a record number of abstract submissions (267), from 33 countries. We accepted 102 abstracts for oral presentations, along with 40 lightning talks and 100 posters.

The theme for this year's conference-Public Health Surveillance - Challenges and Solutions for the Road Ahead - will highlight key challenges voiced by the public health surveillance community. While the science and practice of public health surveillance, in particular biosurveillance, has significantly matured since the initial conference in New York City in 2002, practitioners continue to deal with recurring problems, such as the impacts of reduced funding and appropriate data sharing, as well as new ones - emerging infectious diseases such as MERS-CoV, Chikungunya, and Ebola, as well as novel data sources from meaningful use and various social media. Many of the abstracts selected for oral and lightning presentation take a nuanced approach in examining some of these issues.

In addition, we are delighted to have five notable plenary speakers who have expertise in addressing some the larger problems facing public health today. Dr. Ziad Memish from Saudi Arabia will deliver the opening plenary on surveillance for mass gatherings. ISDS founding member and National Coordinator for Health Information Technology, Dr. Farzad Mostashari will present at the awards ceremony. On the second day, Dr. Don Weiss from New York City Department of Health and Mental Hygiene and Dr. Kari Yacisin from the CDC Epidemic Intelligence Service will present on their experiences with the current Ebola outbreak. Finally, Dr. Linda Rae Murray from the Cook County Department of Public Health will discuss social determinants of public health in the closing plenary.

We are excited with the program for the 2014 conference. We believe the ISDS is a unique society, successfully bringing together individuals from public health practice, industry and academia.This community is the driving force behind the ISDS, and the annual conference is your meeting. We are looking forward to seeing you there.
Ian Painter, MSc, PhD

University of Washington

2014 ISDS Scientific Program Committee Co-Chair

José Lojo, MPH

Philadelphia Department of Public Health 2014 ISDS Scientific Program Committee Co-Chair 